\title{
A AVALIAÇÃO NA EDUCAÇÃO BÁSICA: ENFRENTANDO OS LIMITES DA RESPONSABILIZAÇÃO VERTICAL ${ }^{1}$
}

\author{
EVALUATION IN BASIC EDUCATION: OVERCOMING THE LIMITATIONS OF \\ VERTICAL RESPONSIBILITY
}

Mara Regina Lemes De Sordi ${ }^{2}$

\section{Resumo}

Este ensaio problematiza os modelos de avaliação externa, ranqueadores e meritocráticos, que norteiam as políticas públicas educacionais oficiais e as repercussões na forma de organização do trabalho escolar. Fomenta a reflexão sobre a multidimensionalidade do fenômeno educacional recuperando por meio de investigação desenvolvida na rede municipal de Campinas, outras qualidades existentes nas escolas e subestimadas pelas políticas de avaliação em condição de hegemonia. Por fim, reforça a relevância de processos de avaliação institucional participativa (AIP) como resposta propositiva das redes de ensino aos vieses de políticas públicas centradas em metas que desconsideram a formação humana como direito dos estudantes e dever da escola. Advoga-se em favor de novas formas de construir qualidade na escola incluindo os atores e implicando-os na consecução de metas eivadas de compromisso social.

Palavras chave: avaliação institucional; escola pública; políticas públicas, responsabilização participativa; formação humana.

\begin{abstract}
This essay offers a critical view on the external evaluation guided by the principles of raking and meritocracy which frames the current educational policy, and criticizes the policy's effects on the organization of school. Drawing on an investigation carried out at the Municipal Educational System of Campinas, this essay discusses the multidimensionality of educational phenomenon by shedding light on other "qualities" developed by schools which are side-lined by the currently hegemonic evaluation policies. Finally, it highlights the Participatory Institutional Evaluation Policy (AIP) as an important reaction against the narrow goals set by public policies, which overlook the "human development" as a students' right and a school's responsibility. It stands up for new ways of building educational quality, capable of including all social actors and involving them in the achievement of socially committed goals.

\footnotetext{
${ }^{1}$ Texto apresentado na mesa redonda: Políticas Públicas (ações na educação básica) no II Simpósio de Pesquisa em Educação - SIPED promovido pelo Departamento de Educação da Universidade Federal de Lavras, março 2018.

${ }^{2}$ UNICAMP-Campinas-SP-Brasil- email: maradesordi@uol.com.br
} 


\section{OO DEVIR EDUCAÇÃO}

ISSN: 2526-849X

Keywords: institutional evaluation; public school; public policies; shared responsibility; human development.

\section{Introdução}

Recuperar as bases das atuais políticas públicas educacionais que têm orientado as escolas a percorrerem determinadas trilhas rumo a uma qualidade abstratamente definida, parece sempre enfoque necessário ainda que não mais original no debate acadêmico. Sobejamente, denunciam-se os desdobramentos e equívocos das políticas de responsabilização vertical (re)conhecidas como formas de accountability forte. Alinhadas pela tríade responsabilização vertical, meritocracia e testes padronizados, o que se depreende deste movimento liderado pelos reformadores empresariais é a legitimação da privatização na e da escola pública.

Segundo Freitas (2016, p 141) a privatização é a destinação final das políticas dos reformadores empresariais, pois advém da crença de que a melhoria da qualidade educacional se dá pela concorrência em mercado aberto, tal como no interior dos negócios. O mercado depuraria as instituições de menor qualidade, mantendo apenas as de maior qualidade. Sem muito esforço, podemos inferir os problemas advindos desta transposição simplista de lógicas (mercado-escola) pela marcante distinção que existe entre suas funções finalísticas. Neste sentido, a comparação entre instituições educativas descolada das intencionalidades presentes em seus projetos pedagógicos tende a causar certa confusão acerca de qual referente avaliativo é chamado para atestar a presença de qualidade ou a ausência de qualidade.

A falta de transparência na explicitação da concepção de qualidade que referencia o processo de avaliação das instituições educativas contribui para que não se enfrente a espinhosa questão sobre os interesses ambíguos e contraditórios que atravessam esta definição. Logo, qualidade para uns pode ser falta de qualidade para outros segmentos sociais. A padronização dos processos de regulação servem para a fixação e indução de uma qualidade determinada que passa a ser compreendida como "a" qualidade adequada, uma qualidade pret-a-porter, massificada e tornada soberana.

Está em jogo nessa política a disputa pelo controle tanto da "gestão" escolar como do próprio "processo formativo" da juventude (objetivos, métodos e conteúdos) (FREITAS, 


\section{OO DEVIR EDUCAÇÃO}

ISSN: 2526-849X

2014), ambos aspectos fundamentais para o controle ideológico da escola e seu alinhamento à lógica das necessidades do aparato produtivo.

Se é fato que tais políticas têm produzido muitos efeitos na forma de organização do trabalho escolar, nem por isso poderemos considerar que suas repercussões são monolíticas e que a comunidade as aceita de modo inexorável. Reside ai a esperança ativa que atua e influi. E esta se afasta radicalmente da esperança passiva e conformista que fica à espera, desesperada.

As políticas de responsabilização verticalizadas encontram seu limite na porta da escola, ou seja, na política interna complexa das escolas. As tentativas de verticalizar a "adoção" de índices no interior da escola fracassaram. O exemplo mais significativo disso são os 30 anos de políticas verticalizadas nos Estados Unidos (KORETZ, 2008; 2017). Os avanços nos índices foram pequenos e os efeitos colaterais grandes e perversos para os jovens e para os profissionais da educação (OBEDUC, 2018).

Vale portanto, destacar que a crítica aos testes estandardizados não busca desprezar suas eventuais contribuições no campo da qualidade. Mas pretende desocultar as mazelas decorrentes desta forma de conceber e medir a qualidade educacional advertindo sobre os seus efeitos deletérios. Estudos apoiados em dados empíricos rigorosos fortalecem os debates críticos e se contrapõem ao discurso que desqualificava a priori quaisquer contrapontos às políticas de responsabilização vertical alegando seu viés ideológico.

Há que se enfrentar de modo sério esta gramática gestionária no campo educativo que tem naturalizado a performatividade socialmente improdutiva, a excelência tecnicista e a competitividade cega que ceifam práticas de solidariedade indispensáveis para recuperar o sentido do Bem Comum. E isso nos joga na disputa dos valores que regem os modelos avaliativos indicando as vertentes que os determinam: mais humanas e compreensivas ou vertentes mercadológicas. A que referente avaliativo nos filiamos é pergunta nevrálgica que esclarece o quanto nos aproximamos ou distanciamos da formação humana como fio condutor e ordenador do projeto educativo das escolas e de suas opções curriculares.

Sem este esclarecimento a avaliação da qualidade da escola pode se tornar ambígua e desta ambiguidade resultam equívocos e distorções que penalizam os estudantes e seu projeto de futuro como cidadãos de um mundo que precisa dos valores da cooperação humana, de 


\section{OO DEVIR EDUCAÇÃO}

ISSN: 2526-849X

uma ética edificante que não se conforme e nem se habitue à injustiça social, opacificada pela narrativa meritocrática.

A avaliação que se enraíza no principio da igualdade abstrata acaba produzindo desigualdade concreta. Em larga escala, perpetua a lógica da comparação e da hierarquização e introduz subliminarmente o sentido de responsabilização unilateral culpabilizando determinados atores. Ao assentar-se na padronização com vistas à paridade, cria a falsa ideia de justiça social. Neste sentido, cabe problematizar que ao princípio da igualdade de oportunidades há que se acrescer o compromisso com a construção de condições mais equânimes de vida, sem as quais indicadores de desvantagem social continuarão afetando de forma desigual, estudantes e professores que coexistem nas escolas, submetidos a políticas que os enxerga de modo míope e uniforme. Talvez fosse o caso de pensar uma avaliação que respeite as disparidades afastando-se de um discurso falsamente paritário. Em síntese, uma avaliação díspare no dizer de Mantoan (2018) em tempos de uniformização forjada, pode ser signo de inovação no campo das políticas educacionais.

A identidade da escola pública engendra-se neste contexto conflituoso e altamente regulado pelas políticas de avaliação e as respostas delas oriundas, evidenciará se ela (escola) se comporta como uma comunidade educativa fortemente enraizada no território e sensível às necessidades locais ou como uma empresa educativa, preocupada com resultados efêmeros, fabricados pelo viés do treinamento para os testes que se obtém às custas da exclusão dos segmentos mais frágeis socialmente falando.

Em meio a esta conjuntura fortemente marcada pelo ethos da competitividade, a escola pública pode e deve resistir às pressões que sofre seja do Estado, do mercado, das famílias para que se organize e responda às demandas que se lhe impõe externamente. A forma de respostas que for capaz de produzir nos indicará sua opção, consciente ou não, de como quer se constituir na relação com seu entorno. Trata-se de ver como ela reage às regras do jogo avaliativo, reinventando ou não, possibilidades emancipatórias. Algumas vezes, certa desobediência pedagógica aos padrões de qualidade que nos vem sendo impostos, pode retratar a coragem cívica (AFONSO, 2012) que estamos dispostos a praticar.

\section{A avaliação como produtora de qualidade. Mas qual? Para quem?}




\section{DEVIR EDUCAÇÃO}

ISSN: 2526-849X

Se vivemos em tempos de avaliação e sob o domínio de sua lógica de ação excludente e hierarquizadora; se tentam nos convencer de que a qualidade de um produto é dependente da quantidade de vezes em que este é avaliado; se interiorizamos a ideologia do dom para justificar os índices obtidos e mais do que isso se aprendemos a culpabilizar alguns atores sociais recaindo sobre eles unilateralmente a responsabilidade pelo fracasso do projeto educativo da escola, temos que admitir que ajudamos a perpetuar uma cultura de avaliação nada formativa, nem tampouco solidária e porque não dizer uma cultura de avaliação centrada no medo e favorecedora de dissimulações. Ajudamos a perpetuar as sutilezas perversas da avaliação ocultadas pela confiança quase que sagrada nos números que a avaliação faz circular.

Uma avaliação com feição educativa e produtora de sentidos socialmente pertinentes precisa se afastar desta lógica da exterioridade e voltar a fixar-se e enraizar-se no interior das escolas com o concurso dos atores da comunidade.

Sem que estes atores se envolvam no processo de qualificação das escolas, sem que se reconheçam como sujeitos protagônicos e dispostos a conviver e aprender com seus diferentes saberes e valores, examinados de modo negociado e eticamente implicado, tendem os dados de avaliação produzidos sobre a escola a permanecerem distantes do cotidiano e pouco úteis ao processo decisório eivado de intenções transformadoras da realidade.

Como lembra-nos Kramer, a partir das ideias de Bakthin, no que concerne ao agir ético, o maior desafio de uma educação que se concebe como resposta responsável é garantir o conhecimento do mundo e o reconhecimento do outro.

Trata-se de compreender que, ao contrário de uma formação pragmática em que todo conhecimento deve ter utilidade, ou (dito de modo simples) deve servir, a escola se volta radicalmente para uma formação ética e política em que o conhecimento pode não servir, mas deve atuar na direção da liberdade e da emancipação [...]. O agir ético como responsabilidade significa a presença ativa, a não indiferença, o inverso da omissão e do esquecimento. Trata-se de deixar claras as marcas de nossa atuação de modo que os rastros da história não sejam apagados (KRAMER, 1993, p. 32-33). 


\section{OO DEVIR EDUCAÇÃO}

ISSN: 2526-849X

Avaliar a qualidade de uma escola, de um projeto educativo é examinar as marcas que precisam ser levadas em conta e isso é questão ético-política que não comporta neutralidade. Esta é a grande questão que perpassa os modelos avaliativos de cunho uniformizante, indutores de marcas que pautam-se numa aplicação técnica de conhecimento (SOUZA SANTOS, 1996) e que se negam a reconhecer o outro como sujeito pensante, plural, contraditório que não pode ser moldado simples e impunemente.

O campo da avaliação é reconhecido como impregnado de interesses nem sempre conciliáveis e isso nos leva a discutir os vieses do processo. Um dos mais significativos ligase ao dilema da composição das variáveis que expressam os resultados do trabalho da escola e que afetam os referentes avaliativos. A força deste consenso fabricado em torno dos índices de qualidade educacional precisa ser desconstruída. Ou teremos que admitir que o fenômeno educativo, de alta complexidade social, pode ser reduzido a uma relação composta por fluxo e proficiência, objetiva e neutramente medidos.

Tantas vezes nos sentimos incomodados com esta questão desafiadora que decidimos reagir propositivamente a ela, pesquisando a realidade de uma rede de ensino municipal na qual pesquisadores e estudantes da universidade pública local se sentiam participes e dispostos a exercer certa reconfiguração dos contextos de prática junto aos coletivos das unidades escolares, em especial os profissionais da educação.

\section{O caminho metodológico, apenas um caminho dentre tantos}

Em outros estudos temos discutido exaustivamente a impropriedade de aceitar de pronto, a perspectiva bidimensional presente na constituição dos índices que são usados para estratificar as escolas de uma rede de ensino.

A defesa da multidimensionalidade do fenômeno educativo devidamente contrastada com o ideário da formação humana tem nos motivado a diversas aproximações investigativas tais como a financiada pelo OBEDUC/CAPES (2013-2018) e desenvolvida para propiciar 


\section{OO DEVIR EDUCAÇÃO}

ISSN: 2526-849X

maior clareza das coisas que a escola produz e que não são levadas em conta nos testes estandardizados, justificadas por razões de todas as ordens .

A preocupação metodológica central da pesquisa era com a criação de um arcabouço de avaliação multidimensional passível de ser usado em larga escala e que instrumentalizasse as escolas para re-significar os dados da avaliação externa (Prova Brasil, IDEB).

Cada vez mais os especialistas consideram que as medidas educacionais não podem ser unidimensionais e devem abarcar mais aspectos das crianças e das escolas (KORETZ, 2017). As recentes mudanças introduzidas nos Estados Unidos no falido programa No Child Left Behind e que resultaram na nova lei ESSA - Every Student Succeeds Act - já dispõem que os Estados americanos devem introduzir mais de uma dimensão de avaliação em suas avaliações de larga escala (OBEDUC, 2018).

O cerne da questão investigativa era saber que qualidades outras a escola produz e que são sumariamente negligenciadas pelas atuais políticas que as esquecem e/ou as menosprezam em uma verdadeira tecnologia de subtração dos valores, das aprendizagens colaborativas, dos sentidos da cidadania, do respeito à diversidade e à tolerância, mesmo com todo o avanço das tecnologias de medidas já disponíveis. Assim, nada justifica o abandono de dimensões mais amplas e subjetivas constitutivas da qualidade da escola pública a partir do argumento de que dificultam a mensuração. Admitir sua existência é insuficiente quando se reconhece o alto poder de indução da avaliação. A propalada indagação "vai cair nas provas?" por si só explica o risco de deixarmos descobertas dimensões que afetam o desenvolvimento humano das novas gerações e que precisam nortear a organização do trabalho escolar acreditando que nada se perde com esta opção.

As qualidades produzidas nas 44 escolas de ensino fundamental da rede municipal de Campinas, cenário da pesquisa, captadas por uma coleta de dados diversificada (entrevistas, grupos focais, questionários) geraram uma matriz avaliativa que foi aplicada em professores e alunos, em um esforço de enfrentamento ao reducionismo com que as escolas tem sido avaliadas (autor et al 2016). Nada menos do que 23 dimensões foram lembradas e destas 6 foram priorizadas para permitirem um primeiro avanço no campo das avaliações em larga escala. 
Essas qualidades foram redesenhadas em gráficos radiais - Gráfico 1, aos quais se incluiu os indicadores oficiais de qualidade e que buscavam expressar a multidimensionalidade do fenômeno educativo e as formas bastante particulares que as escolas elegem para produzir qualidade, ultrapassando a perspectiva bidimensional privilegiada pelo IDEB.

Importante citar que a morfologia dos gráficos se afastou da lógica de ranqueamento entre escolas e visou fomentar a aprendizagem relacional das dimensões de qualidade que estão ocorrendo e que se explicam a partir da realidade de cada escola. O gráfico apresenta os valores médios, mínimos e máximos encontrados entre as escolas da rede, explicita a percepção dos professores respondentes acerca da Qualidade Social. Para a interpretação dos resultados encontrados, os valores têm o seguinte significado na escala Likert: 1-Nunca; 2Raramente; 3- Às vezes; 4- Geralmente; 5- Sempre.

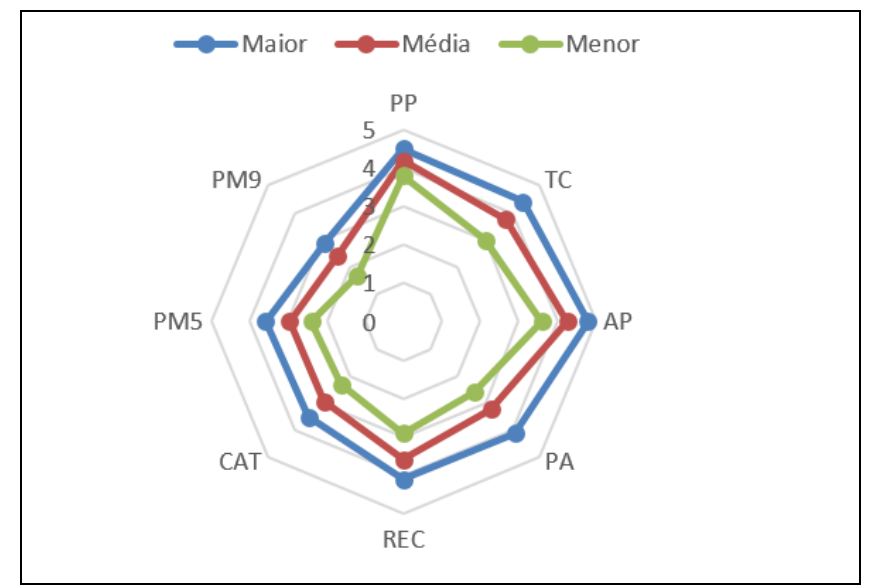

Gráfico 1 - Resultado Geral das escolas

Legenda: Práticas Pedagógicas (PP); Trabalho Coletivo (TC); Acesso e Permanência (AP); Participação (PA); Relação Escola-Comunidade (REC) e Compromisso com a Aprendizagem de Todos (CAT); PM5- proficiência média $5^{\circ}$. ano (Ideb) e PM9- proficiência média $9^{\circ}$. ano (Ideb).

Fonte: Dados da pesquisa

Os dados obtidos puseram em relação essas qualidades e mesmo admitindo que não dão conta da totalidade de coisas que a escola faz ou da totalidade de dimensões reveladoras 


\section{OO DEVIR EDUCAÇÃO}

ISSN: 2526-849X

da qualidade do fenômeno educativo, constituem-se inovações no campo da avaliação da qualidade da escola pública, desenvolvida em larga escala.

Fica claro que o reconhecimento da multidimensionalidade da avaliação pode acelerar mudanças nas políticas de avaliação em larga escala de modo a que se percebam formas alternativas de expressão da qualidade social fomentadas por modelos mais enraizados na realidade das escolas. Tudo isso sem prejuízo da Avaliação Institucional Participativa - AIP, espaço em que, sem sombra de dúvidas, se fortalece a ação coletiva em favor de uma escola includente e socialmente mais justa, na qual o direito à permanência na escola seja sempre associado ao direito à aprendizagens amplas para todas as crianças e jovens.

Nesse sentido, uma avaliação regida por uma escala multidimensional é tida como avanço no campo da avaliação em larga escala, mas requer o fortalecimento da AIP para que os atores da escola conheçam suas fortalezas e fragilidades nas diferentes dimensões, construam uma linha explicativa dos problemas, consensuem e deliberem sobre os caminhos a percorrer, devidamente priorizados, em uma linha do tempo longitudinalmente acompanhada. Os pressupostos da avaliação formativa perpassam todo o processo vivido pelos diferentes atores envolvidos na construção de qualidade confirmando os valores da participação, da escuta sensível ao outro, do diálogo franco com direito ao confronto honesto de posições subsidiando a negociação plural, objetivada pelo interesse comum.

\section{A avaliação da escola, na escola e pela escola: Os meandros da avaliação institucional participativa}

Defendemos que índices podem e devem ser aperfeiçoados para possibilitar leituras mais inteligentes da qualidade educacional produzida pela escola e seus atores. Porém, índices serão sempre expressão menor de tudo o que acontece na vida da escola e que concerne a qualidade. Devem, no entanto, servir para localizar o estágio da escola em relação a determinadas e variadas dimensões. Isso feito, diagnosticado o estágio atual da escola, as "medidas" informadas precisam ser apropriadas, relativizadas, reconvertidas pelos atores da escola por meio de exercícios intensos e plurais de interpelação de seus sentidos para que possam gerar consequências que beneficiem o coletivo escolar.

Revista Devir Educação, Lavras, vol.2, n.2, p.78-89 jul./dez., 2018. 


\section{QO DEVIR EDUCAÇÃO}

ISSN: 2526-849X

Quanto mais a avaliação se desterritorializa da escola, mais se afasta do viés formativo e iluminador de novos caminhos que expressam sua finalidade e mais se comporta como tecnologia de poder. Logo a qualificação da escola não pode prescindir da AIP como instância mobilizadora dos atores para que juntos e organizados, construam a qualidade social.

A ressignificação da concepção de qualidade, encontra nos processos de responsabilização partilhada (Autor; FREITAS, 2013) a possibilidade de reunir as forças progressistas da escola de modo a produzir novos consensos, nascidos do confronto amadurecido entre as visões de qualidade disponíveis e aquelas que precisam emergir, anunciando possibilidades de desenvolvimento humano para todas as crianças e jovens que frequentam a escola pública e dela dependem para a inclusão real na sociedade.

A produção de novas formas de agenciamento dos profissionais da escola favorecida pela AIP, desestabiliza a naturalização de que qualidade da escola é algo resolvido pelas esferas do poder central e as quais nada há a acrescentar.

Pode-se criar, via pesquisa e ou práticas escolares engendradas a partir da ideia de coletivos organizados para a produção da qualidade (CECCIN, 2005), novas indagações sobre as marcas da qualidade que queremos deixar registradas historicamente na escola pública. Novas relações entre a qualidade que vem de fora (avaliação em larga escala) e qualidade produzida desde dentro (avaliação institucional) precisam de espaço institucional para que exercícios de responsabilização participativa possam ocorrer. Trata-se de aprender a conviver e concretizar relações não maniqueístas. Relações críticas convocam a olhares mais amplos e circunstanciados sobre a escola, em busca de uma visão de totalidade, que expresse consensos construídos de modo negociado, conflituoso, plural. Consensos que se construam a partir de escuta ativa dos atores, implicada com interesses sociais e não mercadológicos.

Se admitirmos que as políticas, mesmo as de cunho neoliberal, hoje aparentemente monolíticas, podem ser desestabilizadas por meio da interpelação de seus sentidos e reinvenção de estratégias, o contexto de influência dos atores escolares pode ser favorecido pelo oferecimento de "pistas" iluminadoras do olhar para outras qualidades desenvolvidas pela escola, fadadas ao esquecimento em função do absolutismo dos índices bidimensionais. A avaliação institucional participativa ajuda os coletivos escolares a atuarem responsavelmente no contexto da prática. 


\section{QO DEVIR EDUCAÇÃO \\ ISSN: 2526-849X}

Admitindo-se a complexidade do fenômeno educacional e a dificuldade de esgotar as múltiplas dimensões que o constituem, não enfatizamos soluções definitivas para a questão da regulação da escola, mas defendemos a valorização dos avanços, construídos desde o chão da escola e oferecidos aos gestores das redes de ensino para que façam circular outras possibilidades de accountability inteligente (AFONSO, 2012) exercitando processos democráticos traduzidos pelo diálogo, participação e negociação entre atores sobre aquilo que os aproxima de um projeto educativo emancipatório. Trata-se de assumir a AIP como categoria mobilizadora da escola na direção da reafirmação do trabalho socialmente relevante que faz, em nome do direito das crianças e jovens a uma escola pública, que não se contenta em ser mero espaço de treinamento para os exames externos. Em última instância, trata-se de assumir corajosamente os rastros que queremos deixar quando observamos, criticamos as políticas públicas na educação básica e decidimos atuar ética e responsavelmente sobre elas.

\section{Referências}

AFONSO, Almerindo. J. Para uma conceptualização alternativa de accountability em educação. Edu. Soc., Campinas, v. 33, n. 119, p. 471-484, abr.-jun. 2012.

CECCIN, Ricardo B. "Recursos humanos em saúde", leia-se "Coletivos organizados de produção em saúde." Desafios para a educação. In: PINHEIRO, R\& MATTOS, R.A. Construção social da demanda. Direito à saúde. Trabalho em equipe. Participação e espaços públicos RJ: IMS/UERJ- CEPESC-ABRASCO, 2005, p. 161-180.

FREITAS, Luiz C. Os reformadores empresariais da educação e a disputa pelo controle do processo pedagógico na escola. Educação \& Sociedade, Campinas, v. 35, n. 129, p. 10851114, out./dez. 2014.

FREITAS, Luiz C. Três teses sobre as reformas empresariais da educação: perdendo a ingenuidade. Cad. Cedes, Campinas, v. 36, n. 99, p. 137-153, maio-ago., 2016. Disponível em: <http://www.scielo.br/pdf/ccedes/v36n99/1678-7110-cedes-36-99-00137.pdf> Acesso em: 10 mar. 2017.

KORETZ, Daniel. Measuring Up: what educational testing really tells us. Cambridge: Harvard University Press, 2008.

KORETZ, Daniel The Testing Charade. Pretending to make schools Chicago, University of Chicago Press, 2017. 


\section{DEVIR EDUCAÇÃO}

ISSN: 2526-849X

KRAMER, Sonia A educação como resposta responsável: apontamentos sobre o outro como prioridade. In: FREITAS, M.T (org.). Educação, arte e vida em Bakthin. Belo Horizonte: Autêntica Editora, 2013. P.29-46

MANTOAN, Maria Tereza. Aula inaugural. Mestrado Profissional em Educação Escolar do Programa de Pós Graduação da Faculdade de Educação da UNICAMP, março 2018.

OBEDUC/ CAPES, A Qualidade da Escola Pública: um estudo longitudinal para sustentação da responsabilização partilhada em uma rede de ensino Relatório técnico, Faculdade de Educação, UNICAMP, Campinas, 2018

Autor; VARANI, A.; MENDES, G. S. C. V (Orgs.). Qualidade(s) da Escola Pública: Reinventando a Avaliação como Resistência. Uberlândia: Navegando Publicações, 2017. (acesso gratuito ao ebook: https://www.editoranavegando.com/qualidade-s-da-escolapublica).

Autor., FREITAS, Luiz C. Responsabilização Participativa. Revista Retratos da Escola, Brasília: v. 7, n. 12, p. 87-99, jan./jun. 2013.

Autor; et al. Indicadores de qualidade social da educação publica avançando no campo avaliativo. Estudos em Avaliação Educacional (Online), v. 27, 2016, p. 713-753. Disponível em: http://publicacoes.fcc.org.br/ojs/index.php/eae/article/view/4073. Acesso em 24 de maio de 2018.

SOUSA SANTOS, B. Para uma pedagogia do conflito. In: SILVA, H.L.; AZEVEDO, J.C.; SANTOS, E.S. Novos mapas culturais, novas perspectivas educacionais Porto Alegre: Sulina, 1996. P.15-33. 